\title{
ERRATUM TO PAPER KRIŽNA JAMA (SW SLOVENIA): NUMERICAL-AND CORRELATED-AGES FROM CAVE BEAR-BEARING SEDIMENTS, BY P. BOSAK ET AL., AC 39/3
}

In the issue 39/3, Figs. 6 and 11 were not printed correctly due to the technical problems. Some items in printed version are missing on these two figures. Here

are the corrected version of figures together with their captions.
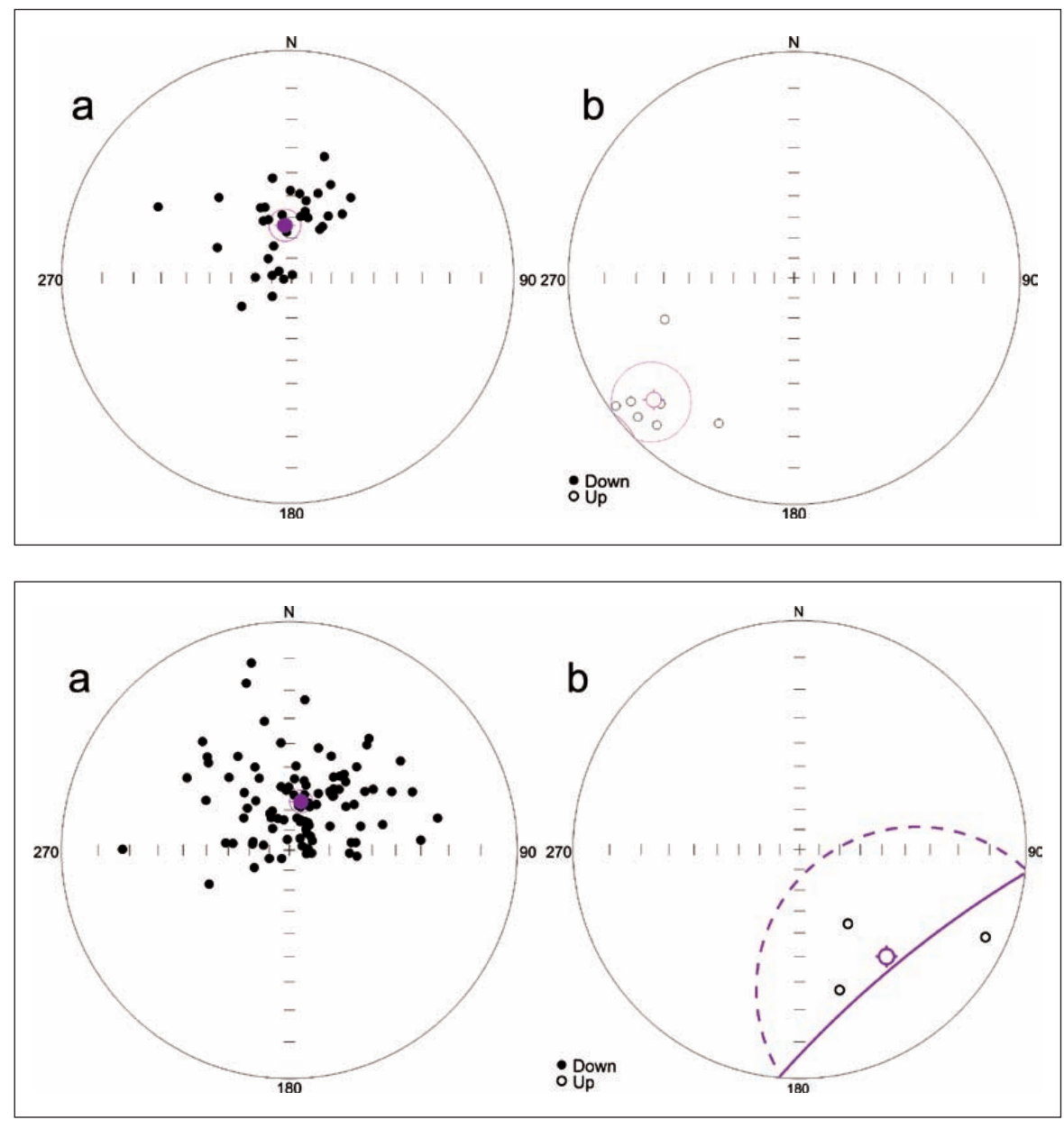

Fig. 6: Directions of C-components of remanence of samples, Križna jama I profile. a) samples with N polarity; a) samples with $R$ polarity. Stereographic projection, open (full) small circles represent projection onto the lower (upper) hemisphere. The mean direction calculated according to Fisher (1953) is marked by a crossed circle; the confidence circle at the 95\% probability level is circumscribed about the mean direction.

Fig. 11: Directions of C-components of remanence of samples, Križna jama II profile. a) samples with N polarity; b) samples with $R$ polarity. For explanations see Fig. 6. 